\title{
EDITORIAL
}

\section{All aboard the European gravy train?}

\author{
As the EU continues to roll out FP7, researchers are asking whether the prize of significant \\ research funding is worth the effort that is involved in applying.
}

We live in a time when governments are beginning to view science as a panacea for an increasingly long list of problems, a realization that is being reflected, in some cases, by an increase in funding. One case in point is the seventh framework programme for research and technological development (FP7), which is the world's biggest researchfunding enterprise and the main avenue for European Union (EU) funding of research from 2007 to 2013. FP7 is the most ambitious EU research programme to date and undoubtedly signals a desire to formulate a stronger role for European research. For each of the next 6 years, more than $€ 7$ billion will be handed out to EU investigators, with the aim of advancing scientific knowledge and, by extension, boosting the region's economy.

Similar to its predecessors, FP7 is divided into different categories, in this case titled 'Cooperation', 'Ideas', 'People' and 'Capacities'. These broad categories refer to the specific objectives of EU research policies, from the funding of multinational research that is too intricate and costly to be carried out at national level, to the training and mobility of young researchers, capacity building and the support of research infrastructures.

'Ideas' refers to the new European Research Council (ERC), an autonomous agency that will fund basic, investigator-driven research. The core of FP7, however, is the $€ 32$ billion 'Cooperation' programme, which will support interdisciplinary, cross-border research collaboration in ten thematic research priorities. Three of these - 'Health' (€6 billion), 'Food, Agriculture and Fisheries, and Biotechnology' ( $€ 1.9$ billion) and 'Environment' ( $€ 1.8$ billion) - are the most relevant themes for microbiologists. Focusing on the 'Health' theme, the overall priorities for infectious disease research include HIV/AIDS, malaria, tuberculosis and emerging epidemics, and although the detailed research topics to be addressed will be different in every call for proposals, these headline areas will remain the priorities. Each priority is obviously important to the future health and prosperity of EU citizens and is rightly deserving of significant research funds, particularly as such funds are becoming increasingly scarce as national funding continues to stagnate in many EU countries.

So, why are European researchers so negative about the programme? The main complaint, as everyone who has submitted an application will testify, is the overwhelming amount of bureaucracy. The paperwork demands are off-putting for many researchers, especially those who are already well funded from other sources, a situation that might deprive many EU-funded projects of the researchers with the most appropriate expertise and experience.

One significant criticism of its predecessor, the sixth framework programme (FP6), was the emphasis on collaborative projects that were carried out by unwieldy consortia with participants from different countries. In addition to being difficult to establish and often requiring 'forced' partnerships, grant reviewers were not free to decide whether the consortia contained sufficient participants from different countries. Also, the selection process and the process of negotiating contracts could frequently take more than 1 year and, following a successful conclusion to these tasks, actually managing the multimillion-euro project was often a thankless proposition, especially for the project coordinator.

Unfortunately, the overall guidelines for FP7 collaborative projects remain largely the same, despite these criticisms. The calls for administrative change, however, have not gone completely unheeded with, most notably, the introduction of a more streamlined application process (the CORDIS website provides a gateway to detailed information about FP7 and is available at http://cordis. europa.eu/fp7/home en.html). There is also a commitment to pay more of the total costs of a research project so that a university does not have to appropriate funds from other activities to sustain the work through to its completion. Other widely applauded developments include the creation of the ERC and its promise to support individual 'bottom-up' research grants on the sole criterion of excellence. The continuation of the Marie Curie Actions has also been welcomed, having helped many young researchers gain experience outside their home countries, with a minimum of red tape.

Of course being the world's biggest programme for research funding brings with it inevitable problems and it remains to be seen whether these changes will placate scientists, promote research and untangle bureaucratic constraints. What is clear is that, despite the programme's complexity, long bureaucratic procedures and the inevitable tough competition, many European researchers are witnessing increasingly tight constraints on their national funding sources and will have to look to FP7 as their best hope to make up the shortfall. Most agree, therefore, that despite the mountain of paperwork, the prize of EU funding is certainly worth the effort. 